\title{
ECONOMIC IMPLICATIONS OF BUSINESS BOUNDARY LAWS
}

\author{
Corwin D. EDWARDs*
}

One of the characteristics of a system of free private enterprise is that private decision establishes the boundaries between administrative control and market bargaining. The relations of business enterprises to each other are determined primarily by a constant and flexible process of negotiation and bargaining which is given an occasional evanescent stability by a long-term contract. The internal organization of each enterprise is based not upon bargaining but upon structure. Materials and equipment are subject to a coordinated control, and even personal services, once the employment relation is established, are subject to continuous direction by the management. In spite of internal conflicts of interest, the institutions of ownership usually channel the activities of an enterprise toward its own greatest profit, whereas the broader organization of an industry and of the economic commonwealth is established by the interaction of frankly conflicting interests.

Generally speaking there are no limits to the shape and direction of an enterprise and no limits to its size other than those ultimate ones which may be established by the laws against monopoly. Those in control may produce any combination of commodities and services, however diverse, and may, as they choose, perform a single operation or the complete series of operations between raw material and consumer. There is room for an infinite diversity in the structure of different concerns, so that short-line producers and long-line producers, handicraft establishments and mechanized plants, single and multiple unit manufacturing companies, producers who buy and producers who make their raw material may exist side by side in the same industry. The grouping of products for joint production or distribution may be so diverse that there are no boundaries between one industry and the next except as they may be arbitrarily defined for some statistical purpose. In distribution the specialty shop and the department store, the independent unit and the corporate or voluntary chain, the consumers' cooperative and the manufacturers'

*A.B., 1920, B.J., 1921, University of Missouri; B.Litt., 1924, Oxford University; Ph.D., 1928, Cornell University. Economic Consultant, Antitust Division, Department of Justice. Formerly, Assistant Chief Economist, Economic Advisor, Federal Trade Commission; Technical Director, Consumers Advisory Board, NRA; Associate Professor of Economics, New York University. Author, Final Report an NRA (Division of Industrial Economics, 1937). Co-author, with J. B. S. Hardman, ed., AmericsN Labor Dynamics (1928); with W. E. Atkins, ed., Economic Behavior (193r); with W. L. Thorp, ed., Economic Problems in a Changing Worzd (1939). Contributor to periodicals. 
outlet may vie with each other in the same city block and may range in size from a glassed-in alcove to a many-storied building.

As the arts of management have been elaborated, many concerns have developed corporate structures within which economic processes are related neither by the armslength bargaining of the market nor by the fiat of a single management, but by a loose managerial alliance, intermediate in character. Equipment companies, management companies, wholly-owned subsidiaries for the manufacture of by-products, marketing subsidiaries, semi-autonomous product divisions, and the like may be viewed for some purposes as separate enterprises and for others as parts of a tight community of interest. For the most part such extrusions of managerial control are likewise unrestrained by authority. The single concern may exist side by side with a bewildering variety of holding company structures.

Insofar as the over-all structural boundaries of business enterprise are determined by private initiative and the arbitrament of market competition, the test for the success of any union of economic processes under any kind of managerial structure is merely its ability to survive. If it appears to offer no advantage to business men, present or prospective, it will not be created. If it cannot resist attacks by other types of enterprise, it will be destroyed. Business types will endure and attain dominance or will disappear and be superseded as an incident of market competition in the same way that biological species undergo an evolutionary selection through their efforts to feed and reproduce.

Business groups which feel themselves threatened in the conflict between different types of business structure are beginning to turn to public authority for aid, and as it becomes apparent that the boundaries of an enterprise may be partially determined by law an increasing number of economic groups undertake a political competition for laws favoring their own type of structure or handicapping some rival type. That every such bill has the backing of one or more economic groups may be taken for granted. The Department of Justice has had occasion to point out in legal proceedings the effort made by certain ice cream manufacturers to establish sanitary requirements which would make it practically impossible for a drug store to manufacture its own ice cream in counter freezers. A bill is now being considered in the California legislature which seeks to limit the activities of chain stores by providing that no enterprise which owns more than two retail establishments may engage in manufacturing. This bill has the backing of certain groups of independent retailers who would like to make it impossible for chains to sell private brands which are not subject to the price control imposed by other statutes; and likewise the backing of some manufacturers who believe they could sell a larger volume with a greater bargaining power if their chain-store customers were deprived of the alternative opportunity to make the goods themselves.

Unfortunately the mere fact that a legislative proposal is intended to advance the competitive interest of some private group is insufficient to discredit the proposal or to indicate its relation to the public interest. If the fighting power of a business 
enterprise were an adequate measure of its efficiency as a source of goods and services, free competition in the determination of business boundaries might be thought undoubtedly desirable. But to a generation which sees no necessary parallel between pecuniary results and economic efficiency, the matter is not so simple. A concern may be strong because it has achieved great bargaining power or because it has reserves which enable it to survive financial shocks that would destroy its rivals. An efficient concern may be weak because it lacks the money to weather a temporary emergency or because it is not armored against an unfair attack. In business, as in international relations, the way of life which makes for security in defense and for power in attack may be sharply different from that which the community would like to encourage.

Since the problems raised by size and corporate structure are dealt with elsewhere in this series of articles, ${ }^{1}$ the issues as to the boundaries of business enterprise which are to be discussed herein will be limited to those involved in selling more than one product or engaging in more than one of the successive stages of production and distribution. Within this field certain outstanding problems may be indicated and illustrated, but the available information is not yet such as to permit a comprehensive account of the extent and relative importance of each problem. ${ }^{2}$

A preliminary distinction must be made between restrictions upon the boundary of an enterprise which express the public authority's desire to restrain trade and restrictions which have other purposes. In the distribution of alcoholic beverages some states forbid the producer to engage in wholesaling and a great many states forbid him to engage in retailing. The underlying theory of such legislation is presumably derived from the widespread belief that the sale of alcoholic liquor is inherently dangerous and that much is to be gained by a close control over the conditions of sale and a restriction upon the quantity sold. Prior to national prohibition, the manufacturers' control over saloons was regarded as partly responsible for efforts to sell liquor in quantities which encouraged drunkenness and conditions of vice and disorder that flouted the wishes of a large part of a community. In some jurisdictions the effort to make alcoholic beverages available without unduly promoting their sale has resulted in a system of state liquor stores intended to destroy the profit incentive in the retail liquor trade. The state laws which exclude the manufacturer from distribution presumably express a milder form of intention to limit the effort to build up a large volume of retail business. They prevent a competitive establishment of saloon outlets similar to the competitive establishment of filling stations which at times has been so conspicuous in the petroleum industry.

Legislation of this kind is obviously inapplicable to the great majority of indus-

\footnotetext{
${ }^{1}$ See Wolf, Monopolistic Competition in Distribution; Feldman, Legislative Opposition to Chain Stores and Its Minimization, both infra this issue.

${ }^{2}$ Cook, Legislative Restrictions on Marketing Integration, stpra this issue, measures the ficld and its subdivisions quantitatively.
} 
tries in which the community accepts the desirability of a larger output and is willing to obtain this output through the ordinary stimulus of the profit motive.

The most obvious issue which is involved in most attempts to enlarge a business by undertaking new types of activities is that of the power which may be exercised by the combination. There are several important kinds and degrees of such power.

When a concern which sells a considerable number of different products has obtained a strong bargaining position upon any one of these products, it is likely to be able to extend its bargaining power to cover the other products as well. The control over the product from which power is derived may be strong or weak; it may be due to a patent, to an unlawful monopoly, to the prestige of a well-advertised brand, or to peculiar qualities in the product itself. Such variations may affect both the number of the customers who find it necessary to buy this product and the degree to which each of them can be coerced. But, in any case, the seller has an opportunity to make his sale of the desired product conditional upon the customer's purchase of other commodities from him rather than from his rivals. By thus forcing his full line into the market, the seller handicaps any other seller who is unable to exercise a similar pressure. If the extent of the seller's power is not sufficient to support an arbitrary requirement that he receive all his customer's trade, inducements may be offered to persuade the customer. Special services and sales helps may be given to the full-line customer but not to others. Discounts may be so arranged that customers who buy less than the full line must pay higher prices. Special offers of the desired products packaged with some of the undesired ones may be advertised to the public at attractive prices. In some cases the exclusion of rival products from the market may be as effective as though purchase of the full line had been flatly required. Other cases may show a reduced effectiveness, to the point at which it is problematical whether the seller obtains any advantage.

The power to win trade by such requirements is greatest when there is no particular reason why the buyer should make his purchases elsewhere. Under such circumstances the attractiveness of the desired product is not likely to be lessened by the restrictions upon its purchase and it probably can be sold at a price as high as though no conditions were attached to the sale. But even if the seller must sacrifice a part of his power to charge a high price for his popular product, he may be richly rewarded by a progressive enlargement of the number of commodities over which he has substantial control. Problems of this kind are so familiar in the administration of the antitrust laws that the public policy applicable to them was crystallized as long ago as IgI $_{4}$ in Section 3 of the Clayton Act, which forbids sales of goods in which either the sale or the price is conditional upon an agreement not to buy the products of competitors. In practice, any arrangement which has the practical effect of preventing purchases from competitors is prohibited by this section. Moreover, where such practices are effective they are likely to be regarded as attempts to create a monopoly and therefore as violations of the Sherman Act. The packers' consent decree, which forbids the great meat packers from manufacturing 
or handling a large number of food products not directly connected with the meatpacking business, is an illustration of the use of the Sherman Act to break up an extension of market control over a longer line of products.

The sale of a variety of products sometimes enlarges the marketing strength of the producer merely because of the number of products sold, even though no one of these commodities may be a source of any special power. Since the customer incurs expense and inconvenience in finding sources of supply and in bargaining with them, he may prefer to obtain his requirements, so far as possible, from a single source. It is notorious, for example, that department stores often have higher average mark-ups than more specialized retail outlets and yet have a more rapid turnover, largely due to the fact that many shoppers find it convenient to remain under one roof. Similar considerations may influence commercial buyers. Moreover, the seller merchandising a large number of products may be able to offer services which could not be readily supplied by a specialized concern. When he ships, he may send carload quantities to communities too small to take a carload of one or two products. With his warehousing and sales expense spread over more products, he may be able to undertake a more intensive sales campaign. The department store may be able to afford a free parking lot; the manufacturer may supply the services of a demonstrator. The mere fact that income is derived from many commodities which are subject to different kinds of demand and different seasonal peaks and which are affected by the different prices for different raw materials may in itself reduce the over-all fluctuations of the enterprise's prosperity. Insofar as these commodities are derived from the same source or are sold to the same customers, the concern handling them may attain an importance for those with whom it deals which cannot be seriously diminished by its price policy or its service in selling any one item. Thus it may attain a degree of freedom from competitive comparison by the mere diversity of its sales.

A variety of products likewise affords the enterprise great attacking power in the competitive sale of any part of its products. Being independent of the revenue from a particular product or product line, the multiple-line producer is free to cut prices much further and continue his cuts much longer than a concern which derives its whole revenue from those products upon which the cut takes place. Therefore, the producer of a limited line of products is likely to be at his mercy. A department store, for example, can adopt a low-price policy upon books with a hope that the general revenue of the store will be increased by customers who are attracted by the book department but also spend money in other departments. The smaller bookseller, however, may find it difficult to match the department store's low prices. This competition between unspecialized and specialized sellers should be sharply distinguished from so-called loss leader selling; for in the mere use of loss leaders the products reduced in price represent only a small part of the trade of any one of the competitors and the price reduction is therefore of much less consequence. The price cutting which a concern selling many lines can undertake against a con- 
cern selling a few is similar to that which can be undertaken by a nation-wide concern against a local one. It covers the victim's whole market, but is of minor importance to the aggressor.

Very frequently, however, the low prices which may be charged upon certain goods in a long line may be developed without malice against any competitor, as an expression of some of the opportunities and economies involved in extending the business. A going concern can often produce or distribute additional products at a relatively low cost. One factor which encouraged the meat packers to go into the grocery business was the fact that they had storage facilities, shipping facilities, and a sales organization well adapted to handle other food products than meat and that consequently they could distribute these products with less additional expense than they would have incurred in building up a separate grocery enterprise. In many lines of manufacture there are scrap or waste products which the management learns to adapt to some useful purpose but which might not be produced if the basic manufacturing processes were not already being carried on for the sake of other commodities. In all such cases, whether the economies arise in production or distribution, the essential point is the fact that since some expenses have already been incurred the additional sales are profitable even if they do not carry their full share of those expenses. Commodities sold under such conditions are always by-products in the sense that they need not cover a proportionate share of the total costs.

A problem arises wherever one concern's by-product is the basic product of a competing concern. Drug stores can outdo electric appliance shops in the sale of simple appliances. Grocery stores can outdo drug stores in the sale of packaged cosmetics or drugs. The convenience outlets for candy and tobacco may often charge prices so low that they would be ruinous to the confectioner or tobacconist. A small-town newspaper may do job printing at rates which cannot be matched by an independent printer. The victims usually insist that low prices thus established constitute unfair competition and are based upon an untenable allocation of costs. The producers of by-products point to their ability to render the same service indefinitely at the same low prices and argue that the public gains by every use of idle facilities and waste materials. When the output of the by-product can become large enough to supply the market, the independent producer of the commodity is probably doomed, for the grouping of product and by-product together in the same enterprise will become typical; but when the market must rely in part upon the independent producer, there may be a long period during which his solvency is intermittently threatened at such times as the total demand is low enough to induce the seller of the by-product to quote low prices.

In some cases strategic advantage lies with the business which handles only a few lines rather than many. This is typically true when some products move more rapidly or require less expense than others with which they have been traditionally associated. A drug store, for example, carries popular lines of packaged drugs which have a rapid sale, less popular lines which move slowly, and various prescrip- 
tion drugs which may be asked for on rare occasions. The time and skill used in filling a prescription are much greater than in selling a packaged product. In the last few years large cities have developed stores which carry only the fast-moving packaged drug items and therefore can do business at a much lower cost than the ordinary drug store. A similar concentration upon the more profitable business is apparent in many food supermarkets.

The development of such low-priced specialty businesses is typically accompanied by insistence on the part of the older enterprises that it is unfair to take the cream of the market and expect someone else to supply the skimmed milk. They argue that the less profitable parts of their activity must be preserved in the public interest and cannot be preserved alone. The defenders of the new concerns which have a narrow scope emphasize not only the importance of business freedom but the desirability of distributing any product as cheaply as possible. From the public point of view, the issue may be defined as a controversy over social cost accounting. Customers for fast-moving lines were formerly asked to subsidize other products. The new way of doing business gives them the opportunity to avoid this subsidy, and will result either in disappearance of the unprofitable products and services, in higher prices upon them, or in a subsidy derived from some new source. The period of readjustment is likely to prove painful to concerns which are already established, but no more so than many of the other changes in the location of the boundaries of business enterprise.

In the union of successive stages of manufacture and distribution there may be problems of competition among concerns of different scope similar to those described above, but such integration also involves special problems not raised by an extension of the line of products handled. The most obvious of these is the squeezing of competitors by a concern to which these competitors must look for their supplies. For many years the Aluminum Company has produced all the aluminum ingot made in the United States and has also been a substantial fabricator of this ingot. Independent fabricators selling in competition with the Aluminum Company have found it necessary to pay the company's price for ingot and to charge prices no higher than the company's for their finished product. Since it was a matter of indifference to the integrated concern whether its profits were derived from ingor or from fabricated products, it was easy to keep the price of ingot high and thus reduce the fabricator's margin. The Bausch Machine Tool Company brought suit on the ground that this device had been used to make the independent manufacture of duralumin unprofitable and thus to extend the Aluminum Company's business in the manufactured products. ${ }^{3}$ Similar charges have been made against the large steel makers, the large copper companies, and various other integrated enterprises. Except where the integrated concern has a substantial control of supply, the availability of materials from other sources makes such a squeeze impossible.

\footnotetext{
${ }^{3}$ Bausch Machine Tool Co. v. Aluminum Co., 72 F. (2d) 236 (C. C. A. 2d, x934), cert. denied, 293 U. S. 589 (1934).
} 
By discrimination in favor of its own distributive outlets an integrated system of manufacture and distribution may decrease the ability of an independent distributor to serve his customers. A recent antitrust proceeding against large motion picture producers and distributors illustrates this possibility. The government charged that theatres which are affiliated with large producers and some chains of theatres not so affiliated were given first choice of pictures and earlier exhibition dates for the pictures they chose. The advantage of such chains was increased by granting them permission to select the features they would exhibit and also to select other features for options or rental contracts which would prevent the first-run exhibition of these features by independents. Independent theatres were required to accept all feature pictures offered by the producer in order to get any of them and were likewise required to accept the producer's short subjects to fill out the programs. Independents were also placed at a disadvantage by high film rentals, discrimination in various fees and services, and requirements that their admission charges for second-run pictures be unduly high.

An experimental decree was entered last fall which protects the independent distributor from the requirement that he accept newsreels and other short subjects; increases his ability to choose among feature pictures by forbidding the lease of such pictures in blocks of more than five; and establishes an arbitration system to deal with the many complicated problems involved in timing the release of pictures to competing theatres. During a three-year trial period, the decree provides, the defendants will not enter upon a general program of expanding their theatre holdings, and the government will not take further steps to divorce production and distribution of motion pictures from exhibition of them. Whether or not the limited provisions of the decree will be sufficient to enable independent theatres to compete effectively with affliates of the producers will appear from experience under the decree.

The attack upon manufacture by chain stores which is now getting under way raises a different issue. Organized groups of independent merchants, particularly in the food field, have been attempting for years to prevent chain stores from underselling them at retail. One stage in this campaign was support for an amendment of the Clayton Act which reduced the opportunity for the chain buyer to purchase goods from the same manufacturer more cheaply than could the independent. Another step was support for state legislation designed to permit the manufacturer of identified goods to fix resale prices which everyone must observe. Although this legislation was of primary interest in the drug trade, in which it hampered price-cutting independents and department stores rather than chains, it was used to some extent in the food industries to control chain-store prices. A third step was support for legislation which forbade sale at retail below cost. However, the food chains have partially escaped the impact of such laws by manufacturing their own products, thus avoiding any issue of price discrimination, and transferring these products to their retail establishments on terms which make possible a low 
retail price. A successful effort to force them out of manufacturing would eliminate one of the remaining means by which they continue to follow their own price policies.

Any general refusal to allow a user or retailer of a product to engage in manufacturing would have the effect in some cases of weakening resistance to the monopoly power of an organized selling group. One reason that industrial concerns, mail-order houses, department stores, and chains can often buy cheaply is the fact that if the price is higher than a reasonable cost of manufacture the purchaser may be in a position to produce the article for himself. Ford has been particularly active in producing a portion of each important article he buys in order to have a check upon the reasonableness of the prices he pays and a nucleus for the expansion of his own output if he cannot buy advantageously.

The joint management of successive processes in production and distribution sometimes involves a special opportunity to be more efficient. The dovetailing of processes in the manufacture of Ford automobiles, for example, has been carried so far that, by previous standards, inventories are negligible. In steel manufacture the close juxtaposition of successive processes often enables a large concern to eliminate in part the cooling and reheating of steel. It also enables an integrated concern to adapt the composition of alloys very closely to the requirements of subsequent metallurgical processes and to experiment freely with both the metal and the means of working it. In so far as a concern produces its own supplies, it is relieved of much of the market uncertainty and the sales activity which are inherent in bargaining relations between independent enterprises.

However, some of the most obvious of the efficiencies developed by vertical integration may be subject to a serious discount for the disturbances which they set up elsewhere in the economic system. The efficiency of the large automobile plant is achieved by creating inefficiencies in the plants which supply it. Deliveries of upholstery material, for example, are ordered, suspended, delayed, cancelled, and reordered as suits the automobile company, often with little regard for the production and inventory cost of the upholstery manufacturer. The inventories of independent sources of supply take the place of inventories in the automobile plant, and the intermittent activity of these independents becomes the basis upon which the automobile producer obtains flexibility without waste.

Moreover, a vertically integrated concern loses some opportunities to profit by the misfortunes of others. Though it need pay no unnecessary profits to its controlled sources of supply, it must meet their costs, whereas at times the independent buyer may purchase his supplies at distress prices. Though no exorbitant mark-ups need to be allowed to controlled outlets, the concern which does its own distributing loses the opportunity to use the many distributive outlets which spend more than their mark-up in distribution. It does not get the benefit of the market coverage which can be afforded by a retailing system in which there are often too many stores too close together to make profits. 
The foregoing summary of some of the more obvious problems as to the boundary of an enterprise is intended to illustrate the point that public intervention is sometimes desirable, but that it may easily do more harm than good. Both multiple lines and vertical integration may be used to promote efficiency as well as to extend or consolidate excessive bargaining power. No crude standard which accepts one type of structure and rejects another would be adequate to express the differences between cases.

Intervention by law may take several different forms. It may be based upon the broad principles of antitrust legislation and may ask the courts to decide the applicability of these principles, case by case. It may seek to outlaw particular types of structural relationship, like manufacturing by chain stores, or particular uses of power, like full-line forcing, in statutes applicable to all industry. It may be specifically directed to the problem raised in a particular industry, as are most of the statutes discussed in the immediately preceding article.

The advantage of dealing with such problems case by case under the antitrust laws lies in the fact that the results of a particular expansion of activity in a particular industry become the basis for action. Where no problem of monopoly or of unreasonable restriction of trade has arisen, a business may be left free to attain whatever private and public advantages are associated with the handling of more lines of goods or with a more complete vertical integration. Yet the public authority may act to terminate a program of expansion designed to drive out independents, whether by squeezing their operating margins, by predatory price cutting upon the products important to them, or by any other device. The fact that federal enforcement agencies have been given so little staff that until the last two or three years they could make no serious attempt to enforce the antitrust laws has prevented the efficacy of this procedure from being demonstrated by experience. Even now the funds for enforcing the Sherman Act are probably not more than one fourth as large as they must be if the Antitrust Division is to do a systematic job. The lack of antitrust laws in some states and of adequate machinery for administering these laws in most states has prevented the use of similar technique in dealing with horizontal and vertical combinations of economic processes in intrastate commerce. Nevertheless, the antitrust procedure remains the most flexible means of distinguishing between public and private interests in this field.

The difficulty in outlawing particular forms of structure or of behavior lies in the fact that the statute may prevent much which is harmless or even beneficial. Whether or not manufacture by chain stores is a problem which calls for public action, it is clear that some manufacturers who maintain retail outlets and some retailers who make a part of their own supplies are not thereby causing harm. Indeed, the increase of efficiency and avoidance of exploitation which may sometimes go with vertical integration has been illustrated in the foregoing discussion. There is a distinct possibility that the large distributors at whom the proposed statute is aimed might be able to protect themselves by purchasing the entire output of a 
normally independent producer, whereas smaller distributors would be more effectively prevented from acquiring a control over production.

Similarly, a statute which strikes at full-line forcing raises abundant problems as to borderline practices which have only a limited effect upon competitors but may contribute to low-cost distribution by the concern adopting the practice. The federal statute is designed to deal with the more flagrant restraints rather than with these marginal cases. It is doubtful whether there have been many successful proceedings under Section 3 of the Clayton Act where the situation did not also involve a violation of the Sherman Act.

As to the statutes setting up restrictions in a single industry which are described in Miss Cook's article, the resort to political weapons by private competitors is much clearer to the outside observer than is the public interest which is supposed to underly each such statute. The attack upon the soda fountain lunch is evident in the laws which forbid sale of food in rooms where other commodities are sold. There is obvious question whether the mere presence or absence of other commodities in a room is a significant guide as to whether the vendor has met the reasonable needs of sanitation. The attack upon the sale of appliances by public utilities obviously reflects the interest of independent merchants who are afraid of the marketing advantages enjoyed by utility companies. Where regulation of such sales consists merely in a requirement that the utility operations of the concern be kept separate from its other activities, the statute is obviously useful in preventing confusion in public utility control. But where an attempt is made to handicap or prevent the sale of appliances by utility companies, the public problem involved is often no greater than in many other unregulated instances in which one or more concerns obtain an advantage in a line of business incidental to their principal acitivities.

There is no need to multiply illustrations. At best, legislation which proceeds industry by industry invites the maximum amount of pressure from organized industry groups and creates the maximum difficulty for legislators in maintaining consistent standards of public interest without special favors for particular groups. Undue power acquired by extending the boundaries of an enterprise to cover additional activities is best dealt with, like other forms of undue competitive power, by a statute aimed at the objectionable results rather than at the means and applicable to the entire field of competitive industry rather than to a special group. 